\title{
Empatia e Ética na fenomenologia de Edith Stein
}

\author{
Silvestre Grzibowski* \\ Rudimar Barea*
}

DOI: $\quad$ 10.20399/P1982-999X.2015v1n2pp34-46

\begin{abstract}
Resumo: O objetivo deste estudo é apresentar o tema da empatia proposto por Edith Stein como fundamento para abordagem de perspectivas éticas nas relações humanas. Stein investiga qual é o sentido essencial dos atos de empatia, consequentemente como os seres humanos podem perceber as vivências alheias. $\mathrm{O}$ argumento central do trabalho consiste em ressaltar que no desenvolvimento da investigação sobre o tema da empatia de Stein, é notória a intrínseca relação que se dá com a ética, ao passo que os sujeitos nas relações intersubjetivas são impulsionados a compreender as vivências do Outro, considerando-a como vivência própria, o que leva o sujeito adotar perspectivas éticas com respeito à alteridade. Para evidenciar estes aspectos o estudo contém uma introdução contextualizando a discussão e logo se divide em dois momentos. No primeiro, são destacados os principais aspectos de clarificação fenomenológica que permitem descrever a essência do tema da empatia de Stein. No segundo, discute-se a importância da afirmação dos valores constituídos intersubjetivamente em relação empática e sua contribuição para o fortalecimento da ética nas relações humanas. Por fim, evidencia-se o esforço no curso do trabalho de situar a relação essencial entre o desenvolvimento da empatia e a efetivação da ética no fluir das vivências.
\end{abstract}

Palavras chave: Fenomenologia; Intersubjetividade; Empatia; Ética.

\begin{abstract}
The objective of this study is to present the theme of empathy proposed by Edith Stein as a foundation for ethical perspectives in human relations. Stein investigates what is the essential meaning of the acts of empathy and consequently how humans can perceive others' life experiences. The central argument of the paper consists in emphasize that the development of research on the topic of empathy for Stein, is notorious intrinsic relationship to ethics, while subjects in interpersonal relations are driven to understand the Other's life experiences, considering it as their own life experiences, which leads the individual to adopt ethical perspectives with respect to otherness. To highlight these issues the study contains an introduction contextualizing the discussion and soon divides itself into two parts. At first, the main aspects of phenomenological clarification that allow to describe the essence of the theme of empathy of Stein are highlighted. In the second, the importance of affirmation of the values constituted intersubjectively in empathic relationship and its contribution to the strengthening of ethics in human relations are discussed. Finally, there is evidence of effort in the course of the paper of locating the essential relation between the development of empathy and the effectiveness of ethics in the flow of the experiences.
\end{abstract}

Keywords: Phenomenology; intersubjectivity; empathy; Ethics.

\section{INTRODUÇÃO}

Edith Stein (1891-1942) é considerada uma das principais pensadoras contemporâneas. Isto porque os seus escritos além de serem estudados em diversas áreas do saber, têm dado uma contribuição saudável para a reflexão fenomenológicofilosófica, psicológica, ética, antropológica, teológica e política. Ela circula nessas áreas de conhecimento sem causar muitas divergências, isso se deve ao fato de que, como

\footnotetext{
* Professor de Filosofia da Universidade Federal de Santa Maria (UFSM)

* Mestre em filosofia na Universidade Federal de Santa Maria (UFSM)
} 
pessoa e intelectual, vivia esse dilema, ou seja, estava preocupada com a vida das pessoas e as relações intersubjetivas, que segundo ela deveriam ser respeitosas. Sendo assim, destacamos a originalidade do seu pensamento no campo da empatia e da ética, temas que serão apresentados nesta pesquisa. A problemática que gira em torno da ética na contemporaneidade, tem sido muito estudada pelos filósofos contemporâneos, no entanto, no nosso modo de entender, Edith Stein apresenta uma ética não normativa, que não está fundamentada na razão, uma ética que está enraizada no respeito da pessoa humana, respeitar o Outro, como o Outro de fato se apresenta diante de mim. No entanto, o desafio que se põe é o de tentar entender como os seres humanos podem estabelecer relações éticas que garantam o seu pleno desenvolvimento com dignidade.

O objetivo do nosso trabalho será apresentar o tema da empatia em Stein ressaltando a intrínseca e necessária ligação à ética. Dizemos isso, pelo fato que a empatia segundo Stein, nos dá a possibilidade de conhecer e compreender melhor o

Outro, fortalecendo a subjetividade individual pela intersubjetividade. A intersubjetividade é fundamental para compreender as relações humanas e também para o comportamento que temos em relação aos outros. Com efeito, a empatia se dá como parâmetro para pensar as relações entre os indivíduos, na construção de um agir ético, e por isso a proposta é investigar como a empatia pode ajudar nas relações entre os seres humanos de forma ética.

Stein em sua investigação filosófica quer demonstrar que o ato de empatia é concreto, acontece aqui e agora, executado pelo sujeito, sempre em referência de alteridade na experiência vivenciada. De nossa parte, tentamos mostrar como a filósofa atribui o tema da empatia em sua essência, qualificando as capacidades empáticas dos indivíduos, para se chegar ao conhecimento da consciência alheia, ou seja, no momento que o sujeito passa a se sentir acompanhado por uma vivência originária de conteúdo não originário, ou seja, é uma vivência de Outro/em. A partir dessa perspectiva indica-se que a empatia é um ato de conhecimento da estrutura do ser humano em sua integridade, mas também pode contribuir para a efetivação de relações éticas. Com efeito, temos como escopo para este trabalho demonstrar a relação que se dá entre a empatia e a ética; dois temas contemporâneos muito pertinentes ao debate filosófico.

\section{O TEMA DA EMPATIA PARA EDITH STEIN}


Uma das grandes inquietações das investigações de Stein se dá pela busca de esclarecimento do tema da empatia como ato de conhecimento sui genere, procurando clarear qual é a verdadeira essência da empatia. Levando em consideração o método fenomenológico proposto por seu mestre Husserl, ${ }^{1}$ Stein se propõe a tratar minuciosamente de aspectos que dizem respeito à estrutura dos seres humanos e de suas vivências, valorizando o "eu que vive e conhece" e os "sujeitos alheios", que se estabelecem em relação ao mundo cotidiano da vida. Afirma Stein: "O mundo no qual eu vivo não é só o mundo de corpos físicos, é também um mundo de Sujeitos alheios, outros a mim, e eu sou o conhecimento desta experiência vivenciada" (2003, p. 70).

Para Stein, o fenômeno que leva o sujeito ao encontro do mundo das coisas e o mundo de outros sujeitos se estabelece pela empatia. É preciso, com efeito, levar em consideração que este fenômeno não se dá somente com o corpo físico, mas também com o corpo próprio dotado de sensibilidade ${ }^{2}$. Ou seja, para Stein nos estabelecemos em relação com "um eu capaz de ter a sensação, de pensar, de sentir, de querer, de agir, como corpo que não faz parte somente do meu mundo fenomênico, mas o próprio centro de orientação de um similar mundo fenomênico [...] com o qual eu estou em uma troca recíproca" (2003, p. 70). Nesse sentido evidencia-se a presença do Outro, que está em troca recíproca que compreendo por empatia.

A empatia se dá na relação essencial do Eu e o Outro. Ou seja, assim como "eu" sou o centro de orientação do meu mundo fenomênico 3 e o "outro" é parte deste mundo, o Outro tem diante de si um mundo fenomênico similar, o qual se orienta para com as

\footnotetext{
1،Edith Stein é fenomenóloga. Portanto, para acompanhar seu percurso, é preciso conhecer alguns elementos básicos sobre os quais se fundamenta a fenomenologia de Edmund Husserl e ativar a atitude interior da retenção do juízo (epoché), isto é, o colocar fora de circuito os resultados apreendidos até então em todos os campos do conhecimento, sobretudo os advindos das ciências naturais, pois essa é a condição indispensável para aprender em si mesmo qualquer tema tratado e chegar assim à sua essência" (ALFIERE, 2014, p. 17).

${ }^{2}$ Edith Stein dedica boa parte de suas obras para estudar a estrutura do ser humano, e nesta, constata-se a importância do "corpo", que para ela tem que ser considerado em duas dimensões relacionadas intrinsecamente, a estas dimensões são atribuídos os termos do alemão; Köper (se refere ao corpo físico, material, que não nos leva necessariamente a uma atitude reflexiva) e Leib (corpo próprio, corpo vivente). Vejamos nas palavras de Stein: "Quando fechamos fortemente os olhos e estendemos nossas mãos longe de nós, de modo que nem um membro toque em nenhuma parte do corpo, ainda assim não nos livramos de nosso corpo, o corpo próprio. Precisamente essa ligação esse pertencimento a mim, não se pode constituir apenas em percepção externa. Um corpo próprio percebido apenas externamente sempre será só um corpo físico especificamente classificado, singularizado, porém nunca meu corpo próprio" (STEIN, 2003, p. 125 - 126).

3"Relaciono-me com as partes do meu corpo, assim como toda a espacialidade que se encontra fora deste, a um ponto zero de orientamento" (STEIN, 2003, p. 127). Em Husserl: Ideias II § 18 / Meditações Cartesianas $\S 53-\S 55$.
} 
coisas e são sujeitos assim como eu. Nessa orientação, "Eu e o Outro", existe uma troca recíproca, onde se encontram vivências intersubjetivas e são impulsionadas por empatia à busca de conhecer os correlatos das vivências alheias que dão sentido a vida, que confirma o meu existir (sei que o que sinto não é uma vivência só do meu eu, embora seja singular ao meu eu).

Para Stein os seres humanos na relação de entendimento não são apenas mônodas separadas, será preciso considerar o outro, em sua plenitude: "O outro se revela como outro de meu eu, no momento pelo qual me vem dado em um modo diferente do <eu>" (2003, p. 121). Esse outro tem uma vida que é diferente da minha, tem seus valores, sua história, carrega todas as suas vivências, de tal forma que não posso objetivá-lo a partir das vivências. A cada momento em nossas vidas somos impulsionados pela nossa corporeidade em relações intersubjetivas para diante do outro, em um mostrar-se originário aqui e agora, assim como o Outro se apresenta diante de mim, considerando o tempo fenomenológico que não se dilui em um passado ou em um futuro, mas sim em um dar-se no fluir das vivências, como nos fala Ângela Ale Bello: "O eu, se identifica com o inteiro fluir das vivências e nisso consiste a sua vida, e o seu viver está no tempo, no sentido que procede de momento para momento" (2000, p. 89).

Nas relações intersubjetivas do fluir de vivências, temos as possibilidades de perceber o outro através da empatia, e este ato é o que pode dar condições de conhecimento intersubjetivo do mundo cotidiano da vida. Para Stein seria, no entanto, necessário esclarecer como se dá a essência da empatia, que levaria a humanidade ter conhecimentos intersubjetivamente cognoscitivos. ${ }^{4}$ Segundo Stein, para o entendimento da empatia será preciso levar em consideração a seguinte questão: "Como será possível que tudo aquilo que nos aparece em conjunto ao puro corpo físico, dados a nós pela percepção externa, se constitui em conformidade com a consciência” (2003, p. 70). Stein diz que é preciso tomar conhecimento dos diversos modos singulares e concretos das vivências, que se dão entre um individuo e seus próximos. No entanto, a filósofa percebe que existem diversos modos de dar-se, e será preciso colocar em evidência as eventuais relações de fundo, que seriam indicadas pelo termo da empatia:

\footnotetext{
${ }^{4}$ No seu curso sobre a natureza e o espírito, Husserl havia falado de que um mundo objetivo exterior só podia ser experimentado intersubjetivamente, isto é, por uma pluralidade de indivíduos cognoscentes, que estejam situados em uma posição de intercambio de cognoscitivo. (STEIN. 2012, p. 360). Esse curso culminaria no Livro Segundo de Ideias de Husserl, pelo qual Stein foi uma das principais responsáveis pela sua edição.
} 
Todo esse dar-se relacionadas com a experiência vivenciada alheia nos enviam a um gênero de atos no qual é possível compreender a própria experiência vivida alheia. Sobre tais atos se baseiam aquele de articular o conhecimento que queremos agora indicar com o termo "empatia" (Einfühlung), abstraindo do sentido que foi atribuído ao termo em todas as tradições históricas. (2003, p. 71).

Para deixar mais clara a sua posição, a nossa autora quer diferenciar e comparar o seu entendimento da concepção histórica do tema da empatia ${ }^{5}$, sendo necessário deixar claro em primeira mão, a relação da percepção externa e a empatia.

Os atos de percepção externa possibilitam colher intuitivamente a vivência, no momento que recebemos aqui e agora,${ }^{6}$ de modo originário em respeito aos lados coparticipantes, que são, ou não, dirigidas a mim. No entanto, eu posso considerar o lado que me for mais conveniente, e desta forma estar equivocado em relação a um dar-se originário da vivência. Na busca do entendimento das relações intersubjetivas, não se pode ficar apenas em um nível de aparências, será preciso estar disposto para o Outro além do que se apresenta pela percepção externa, há muitos outros aspectos que se apresentam quando a vivência do Outro emerge diante do eu, que não pode objetivá-la por meio de uma percepção externa. ${ }^{7}$ A empatia se dá como um ato de percepção que considera os fatores da percepção externa e interna numa relação não originária por seu conteúdo, mas que acontece originariamente em meu ser, me puxando para dentro da vivência do Outro, a tal ponto de viver a sua vivência como se fosse minha.

\subsection{Viver a vivência do outro como se fosse minha vivência}

O esclarecimento do que se entende por vivência originária e não originária no tema da empatia proposto por Stein é muito importante, Stein está apresentando a possibilidade de lidar com uma vivência que não se dá na esfera do indivíduo preceptor, mas sim na esfera do Outro em Alteridade. Uma relação que coloca o 'ser' que tem seu mundo fenomênico como ponto zero de orientação, desorientado de seu mundo

\footnotetext{
${ }^{5} \mathrm{Na}$ primeira parte do trabalho que fora perdido por circunstâncias desconhecidas se encontra segundo a autora uma descrição histórica dos estudos que envolvem o problema da empatia (2003, p. 65.)

6“'A percepção externa é um tipo de ato, no qual o ser cósmico, espaço-temporal e o seu acontecer, se dá de frente para mim, em carne e osso" (2003, p. 72). Para aprofundamento ver SAVIAN, Filho Juvenal "Empatia Edmund Husserl e Edith Stein": Páginas 35 - 40.

7"Sabemos que a percepção externa é um ato originário licitante. No entanto, admitindo que a empatia não seja uma percepção externa, ainda não pode se dizer, que nesta lhe falte o caráter de 'originariedade"" (STEIN, 2003, p. 73).
} 
fenomênico, guiado pela alteridade do Outro. Por isso o esclarecimento do que se quer dizer com vivências originárias e não-originárias são fundamentais para entender a proposta da empatia e a relação que se estabelecerá com a ética.

Stein afirma que por originalidade deve se entender, "todas as nossas vivências presentes, intensas como tais" (2003, p. 73). A filósofa, parte deste argumento por acreditar que, nada pode ser mais originário na experiência vivida, que a mesma experiência vivida. Mas, nem todas as vivências são originárias pelo seu conteúdo, como se pode observar no caso da 'recordação, da esperança, da fantasia', que não tem seu objeto presente em carne e osso, o caráter de personificação é reivindicado como momento imanente das vivências de empatia.

Para cada vivência existe a possibilidade de um dar-se originário, é dizer, a possibilidade de existir já como corporalmente própria para o olhar reflexivo do eu vivente nesta. Existe ademais a possibilidade de um modo não originário de dar-se das vivências próprias, como na recordação, na expectativa, na fantasia (2005, p. 84).

Edith Stein, afirma que a empatia ganha aspectos de originalidade do qual, pela percepção de seu conteúdo é possível a personificação das vivências: "Se trata de um ato que é originário enquanto vivência presente, entretanto é não originário pelo seu conteúdo (2003, p. 77)". Tomamos o exemplo dado por Stein, para deixar mais claro, como se dá os atos de empatia em sua essência: "Um amigo vem até mim e me diz que perdeu um irmão, e eu percebo a sua dor. O que é este perceber? [...] o que tal perceber é em si, e não por meio de quais caminhos seja possível chegar até ele" (STEIN, 2003, p. 71).

No instante em que o vivido do Outro emerge diante de mim, em primeira instância concebo-o como objeto, na sequência eu posso me dar conta de tal situação, me colocando em seu lugar, de tal forma que a vivência não seja mais objeto, me atraindo para dentro dela, permitindo ser sujeito desta vivência que não é originária minha, mas se anuncia em mim e me convida para viver a sua originalidade descobrindo todas as suas formas de dar-se. Somente depois de esgotado o conhecimento desta vivência é que se poderia tê-la como objeto novamente, ao passo que me volto objetivamente diante do Outro que espera de mim a sua compreensão. Com isso chegaríamos ao cerne do processo empático: "Na minha experiência vivida não originária, eu me sinto acompanhado de uma experiência vivida originária, a qual não foi vivida por mim, mas se anuncia em mim, manifestando-se na minha experiência vivida não originária" (STEIN, 2003, p.79). 
Ficam caracterizados nessa passagem os três graus de atuação da empatia estabelecidos para Stein, através do qual é possível perceber a vivência alheia, a saber: “Os graus são: 1) a emersão do vivido; 2) a sua explicação completa; 3) a objetivação compreensiva do vivido explicado" (2003, p. 78). O primeiro grau é aquele pelo qual a vivência do outro emerge improvisamente diante de mim (o meu amigo neste caso me apresenta sua vivência de dor, alegria...). O segundo vem atualizando essa vivência, no momento pelo qual chego à conclusão de estar envolvido no estado de espírito do outro, busco obter "um dar-se mais claro do estado de espírito no qual o outro se encontra, aquela vivência não é mais objeto em sentido próprio, se não que me tem atraído para dentro de si" (STEIN. 2003, p. 78). No terceiro grau, esta vivência vem objetivada, ela volta para mim como objeto correlativo da consciência, ela se apresenta em contraposição a minha própria experiência vivenciada.

Quando percebo a vivência do outro, ela emerge e transcende o meu ser pela apreensão da vivência do Outro. Esse é o objeto de busca e de clarificação fenomenológica para Stein. Colocar em evidência as características próprias desse ato experiencial, que se dá em uma consciência alheia, da qual, posso compreender de forma transcendental adotando perspectivas éticas nessa relação intersubjetiva que se estabelece no fluxo de vivências. A partir desta perspectiva tomando a empatia em sua plena efetivação, teríamos muito mais cuidado nas relações que estabelecemos com os outros, porém nem sempre esses graus se efetivam nas relações humanas. O que se vê, muitas vezes no cenário contemporâneo é que nem sequer o primeiro grau, aquele pelo qual o vivido emerge diante de mim, é percebido nas relações. E, se o Outro não é considerado em sua plenitude fica em aberto um grande vácuo nas relações intersubjetivas que são intrinsecamente fundadoras da nossa própria existência.

Estes aspectos são identificados por vários pensadores contemporâneos que tentam fugir da lógica individualista, normativa, dentre outros aspectos que não leva em consideração o Outro em suas vivências. Reitera-se para ilustrar essa nossa preposição uma das passagens do pensador Emmanuel Levinas, que ao escrever "Totalidade e Infinito", diz:

O Rosto de Outrem destrói em cada instante e ultrapassa a imagem plástica que ele me deixa, a ideia à minha medida e à medida do seu ideatum - a ideia adequada. Não se manifesta por essas qualidades, mas exprime-se. O rosto, contra a ontologia contemporânea, traz uma noção de verdade que não é um desvendar de um Neutro impessoal, mas uma expressão: o ente atravessa todos os invólucros e generalidades do ser, para expor na sua 'forma' a 
totalidade de seu 'conteúdo' para eliminar, no fim de contas a distinção de forma e conteúdos (2011, p. 38).

Somos chamados, para uma responsabilidade que não pode ser ignorada, que deve fazer com que saiamos da esfera que nos encontramos para um choque de realidade, a empatia nos possibilita esse encontro, mas para que ela possa se dar plenamente é preciso deixar envolver-se na realidade vivenciada pelo outro, na nossa racionalidade, em nosso modo de ser. A busca de estabelecer relações éticas interhumanas não é novidade em filosofia, mas sempre se encontra muita dificuldade para que tal operação seja realizada. O método pelo qual a empatia de Stein nos apresenta é inovador, e quando vivenciado em sua essência nos conduz para contemplar a vida ética. É, portanto, essa relação que se pretende reforçar no item que segue esse trabalho, ou seja, a tentativa será a de responder, como a empatia nos ajuda a adotar perspectivas de abordagem ética nas relações intersubjetivas.

\section{PERSPECTIVAS DE ABORDAGEM ÉTICA A PARTIR DO TEMA}

\section{DA EMPATIA}

A empatia no contexto filosófico de Stein nos dá fundamento para ética, dado que o movimento da empatia atravessa as experiências do dia a dia, que nos impulsionam, para estar sempre se dando conta das vivências do Outro em posição de responsabilidade e alteridade, sendo assim; antes de emitir qualquer juízo, empatizo, me sinto acompanhado de sua vivência como se fosse minha. Chegar-se-ia então, ao conhecimento das experiências vividas em sua essência, como afirma Stein, "chegamos por meio da empatia a uma espécie de atos experienciais sui generis (2003, p. 79)" [Grifos da autora]. Se relacionarmos a experiência da empatia com a ética, nos daríamos conta, que para o nosso conhecimento, é preciso sempre estar atento às experiências que se apresentam a mim, de tal modo, que eu possa perceber o vivido do outro, "como se fosse meu vivido" e somente a partir deste dar-se conta, desencadear uma ação.

Nota-se a relação essencial que a empatia possibilita para o desenvolvimento da ética, visto que é o outro que me da condição de conhecimento e de desenvolvimento, do qual devo respeitar em sua integridade, reconhecer como ser humano próximo e semelhante a mim, que tem as mesmas possibilidades de ação, e que é possuidor dos mesmos sentimentos em sua generalidade, mas que não sou eu, é outro, um alheio. Vejamos nas palavras de Stein: 
Temos afirmado que o significado do conhecimento, que podemos obter da pessoa alheia, também tem o propósito de nosso "auto-conhecimento". Ela não só nos ensina como já visto anteriormente, a se colocar como objeto de nós mesmos, mas carrega o desenvolvimento, enquanto empatia de "naturezas afins", ou seja, de pessoas de nosso tipo, aquele que em nós está dormindo e, portanto, fica claro, enquanto empatia das estruturas pessoais diferentemente formadas, aquilo que somos e o que não somos a mais ou a menos que os outros. Com o que é dado ao mesmo tempo, para além do autoconhecimento, uma ajuda importante para a auto-avaliação. $\mathrm{O}$ fato da vida é um valor fundamental em relação ao seu valor. Desta forma, com os novos valores obtidos por meio de empatia, o olhar se desdobra simultaneamente sobre os valores desconhecidos da própria pessoa (2003, p. 227-228) [Grifos da autora]

Dado que é o outro que dá a possibilidade do autoconhecimento e da autoavaliação dos valores presentes em nossa estrutura de pessoa humana, a empatia sempre deve ser considerada em uma abordagem ética. A afirmação de Stein ao se referir que a vida possui um valor fundamental ultrapassa qualquer concepção que poderíamos obter nas relações intersubjetivas, o que está sendo proposto é um olhar para a dignidade humana sem diminuir em uma concepção de ética normativa, a um valor, a uma determinada regra; a vida que se vive deve ser preservada como valor fundamental, e tudo que venha a ferir esse valor deve ser levado em consideração pela ética. Com efeito, é importante considerar que não se elimina a vida individual, mas sim, cada um se fortalece nas relações, dado que "os dois sujeitos são reciprocamente separados não conectados [...], uma continuidade nas vivências (STEIN, 2003, p. 79)". E é por este aspecto que a empatia também tem em seu método que cada vivência deve ser considerada em sua essência, sem que seja afetada por qualquer espécie de contagio afetivo, emotivo, ou seja, de co-participação, que o sujeito possa estabelecer nas relações intersubjetivas.

A condição do sujeito, com efeito, não pertence a uma vivência solipsista (eo $i p s o)^{8}$, o sujeito surge das relações intersubjetivas com o outro. Essa perspectiva nasce das vivências de relações intersubjetivas que formam o Sujeito da empatia, que não se dá na primeira pessoa - em um eo ipso. De acordo com Stein percebe-se que sempre estamos envoltos de acontecimentos que são relacionados a mais do que uma pessoa, e cada pessoa em relação a este acontecimento, tem a sua peculiar maneira de sentir, de

${ }^{8}$ Edith Stein tem presente no contexto de sua obra a concepção de seu mestre Husserl em Ideias II $\S 43$ a $\S$ 45, do qual encontramos em suma a seguinte concepção: "O sujeito solipsista tem o campo táctil em copresença com as superfícies aparentes do corpo e com este o campo do calor; em segundo lugar tem a localização indeterminada dos sentimentos e sensações comuns (inclusive espirituais), e ademais a interioridade corporal, mediada pela localização do campo táctil [...] Tudo isto está copertencentemente dado para mim mesmo em co-presença, e se transfere logo a empatia: a mão palpante do outro, que eu vejo, apresenta para mim, a visão solipsista desta mão e logo tudo o que tem que pertencer a esta em copresença representada (2005, p. 206 - 207) [grifo do autor]. 
agir, de querer. ${ }^{9}$ Entretanto em todos os acontecimentos eu não sou liberado do meu caráter monádico (assim como o outro também não é), eu tenho uma vivência particular, mas capto por empatia o sentimento do Outro e a partir do percebido, mudo a minha percepção do acontecimento e a minha maneira de agir, querer e sentir. Com efeito, considerando cada pessoa em seu mundo fenomênico, temos um Eu e um Tu, e, é desta relação que para Stein emerge o Sujeito de grau mais elevado, aquele que executa o ato de empatia em sua essência, aquele que está de acordo com a ética por que é capaz de viver a alegria que é experimentada pelo outro, sem fazer confusão com a vivência pessoal. Eis a afirmação de Stein:

\begin{abstract}
Enquanto vivo a alegria que é experimentada por outro, não percebo nenhuma alegria originária: ela não brota de modo vivo de meu Eu, nem tem o caráter de ter estado viva anteriormente como alegria lembrada, muito menos como meramente fantasiada, isto é privada de vida real, mas é precisamente o outro Sujeito aquele que experimenta de maneira viva tal originariedade; a alegria que brota dele é originária, embora eu não a viva como originária (2003, p. 78).
\end{abstract}

É a partir desses aspectos que podemos entrar no campo dos valores, visto que a efetivação de valores partindo de uma pessoa só, não teria validade, e mais ainda; como alguém poderia criar um valor por si só? Os valores são criados mutuamente, e assim deveria ser compreendido mutuamente nesse fluxo de valores, no qual cada um de nós pode se espelhar no seu semelhante, e, perceber se aquele valor cultivado vai bem, e, se vai de encontro ao desenvolvimento da vida humana, assim nos ensina Edith Stein:

Cada apreensão de pessoas de outra espécie pode se tornar a base de uma comparação de avaliação. E o fato de que o ato de antepor ou pospor, freqüentemente vêm a um dar-se de valores, que por si só permanecem despercebidas, com isso, aprender a avaliar, de tempo em tempo nós mesmos acertadamente, do momento que vivemos atribuindo a nós maiores ou menores valores em comparação com os outros (2003, p. 228).

O fortalecimento de valores, portanto não depende exclusivamente de uma pessoa, mas está no fluir das vivências. E nota-se a importância de que o outro se estabelece em relação de empatia comigo, pelo fato que posso compreender seus comportamentos, não vivo seu comportamento, mas posso compreender e valorar em vista um bem comum, uma comunidade regida pela ética, que prima por ser justa com

\footnotetext{
9“'Quando quero efetivamente conhecer alguém, devo deixar de lado tudo o que eu já soube sobre essa pessoa de forma indireta e esforçar-me para apreendê-la por mim mesmo, livre de pré-concepções (ALFIERI, 2014, p. 22).
} 
referência a dignidade humana, desde a sua particularidade, mas também dentro da comunidade de vida. Essa perspectiva é posta mais firmemente em sua obra Psicologia e ciência do espírito: contribuições para uma fundação filosófica:

\begin{abstract}
Quando acontece que uma pessoa se põe de frente a outra, como sujeito e objeto, lhe examina e lhe "trata" segundo um plano estabelecido sobre a base do conhecimento adquirido e através dessas ações se orienta, neste caso, ambos convivem numa sociedade. Quando, ao contrário, um sujeito aceita o outro como sujeito e não está na frente dele, mas vive com ele e é determinado por seus movimentos vitais, neste caso os dois sujeitos formam uma comunidade (STEIN, 1999, p. 159).
\end{abstract}

A aceitabilidade do Outro como sujeito é fundamental para que a ética possa se efetivar. Vive-se em comunidade, numa forma de interdependência, onde é necessária uma ação enquanto sujeito, escapando da superficialidade que se apresenta nas nossas relações cotidianas. No entanto, somos responsáveis também pela nossa comunidade, do qual todos/as participam como afirma Stein: "A aceitação do valor, totalmente preenchido, ele é, portanto, em essência, um sentir que une e, onde não há participação ativa do eu, esta última é representada por uma intenção incompleta (1999, p. 185).” Assim, o valor de um indivíduo é afirmado pelos outros indivíduos viventes da comunidade. Será, no entanto, na relação indivíduo/comunidade que se estabelece um clima propício, não exatamente único, onde a vivência empática pode estabelecer a base para uma vivência ética dos seus partícipes, pela tomada de consciência do outro em sua alteridade, respeitando todos os aspectos que cercam a dignidade da pessoa humana.

O aprofundamento dessa discussão culminaria em outro estudo de Stein: "Uma Investigação Sobre o Estado", do qual a sua preocupação gira em torno da pessoa humana e a realidade que a envolve. Nessa obra Stein problematiza: "De que maneira as normas éticas se aplicam ao Estado" (2005, p. 640). Sabendo que o Estado é composto por sujeitos e sua função é garantir atos livres dos sujeitos (e estes podem ter valor ético positivo e negativo), entraríamos então em um campo problemático para efetivação de um dever ético. Com efeito, Stein afirma que existe então uma grande necessidade do Estado ser "afetado de alguma maneira por exigências éticas" (2005, p. 640). E são as pessoas que estão ao seu serviço que devem contribuir para que "o Estado mesmo instaure o que é justo e não permita que se suceda o que é injusto” (2005, p. 640).

\title{
CONSIDERAÇÕES FINAIS
}


Fica notório com o desenvolver desse estudo a importante contribuição de Edith Stein para a empatia e a ética, temas estes que estão em continua referência no que tange à dignidade humana e o zelo pelos valores adquiridos intersubjetivamente nas relações que se estabelecem contemporaneamente. Ao apresentar o tema da empatia, percebe-se de forma geral a sua contribuição para o entendimento do Outro, e, consequentemente para o fortalecimento da ética nas relações humanas.

No que se refere à empatia ressalta-se o seu importante papel na compreensão das relações humanas. Edith Stein em suas pesquisas tratou de clarear como acontece o ato de empatia nos seres humanos, tema que já era indicado por outros pensadores, mas, que não fora investigado em caráter de essência. Com efeito, essa preocupação de buscar a essência da empatia, lhe ajudou a entender de forma coerente como se dão as relações humanas. Com efeito, a empatia é um movimento cognitivo que possibilita o conhecimento do Outro, a percepção da sua comum-humanidade que jamais pode ser ferida do ponto de vista ético.

Pode-se perceber com o que foi apresentado que a empatia dá a base para a constituição de uma ética. A empatia possibilita o conhecimento da experiência do outro, e sendo assim possibilita colocar-me no seu lugar em determinadas situações. É somente a partir desta perspectiva que se pode proferir um pensamento ético, será preciso adotar a perspectiva de respeito para com as diferenças e semelhanças que o Outro me dá na relação intersubjetiva. Com efeito, nem uma pessoa é autorizada a fazer um julgamento ético de Outra, sem antes passar pelo crivo da empatia, que possibilita ao sujeito que empatiza, experienciar vivência alheia do empatizado como se fosse dele.

Em suma, compreender as relações humanas e agir eticamente só é possível na medida em que o sujeito se sinta acompanhado da vivência do Outro, em que este outro afete o seu pensar, o seu agir, o seu querer e o seu sentir. O conhecimento empático impulsiona os seres humanos a estarem sempre 'abertos' para o conhecimento do Outro, como seu semelhante, aquele que se pode amar mesmo que seja inimigo. Isso só é possível quando objetiva-se a ética motivando-se pelo desejo infinito do Outro, conservando a dignidade do Outro enquanto Outro, assim como preservo o direito que é meu, de viver uma vida boa, de ser digno de sua própria humanidade.

\section{REFERÊNCIAS BIBLIOGRAFICAS}


ALFIERI, Francesco. Pessoa humana e singularidade em Edith Stein: uma nova fundação da antropologia filosófica. Organização e tradução de Clio Tricarico; prefácio de Juvenal Savian Filho. - 1. ed. - São Paulo: Perspectiva, 2014

BELLO, Angela Ales. A fenomenologia do ser humano: traços de uma filosofia do feminino. Trad. de Antonio Angonese. Bauru, São Paulo: Edusc, 2000. (Coleção Filosofia e Política).

HUSERL, Edmund. Ideias para uma fenomenologia pura e para uma filosofia fenomenológica: Introdução geral a fenomenologia pura. Trad. Márcio Suzuki. Aparecida SP. Ideias \& Letras, 2006.

Ideas Relativas a una fenomenología pura y una filosofía fenomenológica: Libro Segundo: Investigaciones fenomenológicas sobre a constituição. Tradução Antonio Zirión Q. México; UNAN, Instituto de Investigaciones Filosóficas, 2005.

- Meditações Cartesianas e Conferencias de Paris. De acordo com o texto Husserliana I; editado por Stephan Strasser; tradução de Pedro M. S. Alves. 1. Ed. Rio de Janeiro: Forense, 2013.

LEVINAS, Emmanuel. Totalidade e Infinito. $3^{3}$ Ed. Tradução de José Pinto Ribeiro. Lisboa Portugal: Edições 70, 2011

SAVIAN, Filho Juvenal (Org.). Empatia Edmund Husserl e Edith Stein: apresentações didáticas. São Paulo, SP: Loyola, 2014.

STEIN, Edith. Il problema dell'Empatia. Trad. de Elio Costatini e de Erika Schulze Cosgtantini. Roma: Edizioni Studium, 2003.

Introduzione alla Filosofia. Traduzido do Alemão por Anna Maria Pezzella. Città Nuova, Roma, 2001, p. 35-50.

La Estructura de la persona humana: Tradução do original alemão (Der aufbau der menschlichen person), por José Mardomingo. Madrid - Espanha; Estudios y ensayos BAC Filosofía y ciências. 2007.

. Obras completas, II: Escritos filosóficos etapa fenomenológica. Bajo la direción de Julen Urzika y Francisco Javier Sancho. Traduzido do alemão por Constantino Ruiz Garrido e José Luiz Caballero Bono. Editora Monte Carmelo, MadridEspanha, 2005.

Obras selectas: $2^{\circ}$ edição preparada por Francisco Javier Fermín. BurgosEspanha; Monte Carmelo, 2012.

Psicologia e ciência do espírito: contribuições para uma fundação filosófica.

Città Nuova: Roma, 1999. 